Volume 7

Issue 1 Special Issue: Understanding Effects of

Impression Management on Assessment

Article 2

Outcomes

2021

\title{
Applicant Faking on Personality Tests: Good or Bad and Why Should We Care?
}

\author{
Robert P. Tett \\ The University of Tulsa \\ Daniel V. Simonet \\ Montclair University
}

Follow this and additional works at: https://scholarworks.bgsu.edu/pad

Part of the Human Resources Management Commons, and the Industrial and Organizational

Psychology Commons

How does access to this work benefit you? Let us know!

\section{Recommended Citation}

Tett, Robert P. and Simonet, Daniel V. (2021) "Applicant Faking on Personality Tests: Good or Bad and Why Should We Care?," Personnel Assessment and Decisions: Number 7 : Iss. 1 , Article 2.

DOI: https://doi.org/10.25035/pad.2021.01.002

Available at: https://scholarworks.bgsu.edu/pad/vol7/iss1/2

This Main Article is brought to you for free and open access by the Journals at ScholarWorks@BGSU. It has been accepted for inclusion in Personnel Assessment and Decisions by an authorized editor of ScholarWorks@BGSU. 


\title{
Applicant Faking on Personality TESTS: GoOd OR BAD AND Why SHOULd We Care?
}

\author{
Robert P. Tett $^{1}$ and Daniel V. Simonet ${ }^{2}$
}

1. The University of Tulsa

2. Montclair University

\begin{tabular}{c}
\hline KEYWORDS \\
personality assessment, \\
faking, validity, self- \\
report, personnel \\
selection, trait-based fit \\
\hline
\end{tabular}

ABSTRACT

The unitarian understanding of construct validity holds that deliberate response distortion in completing self-report personality tests (i.e., faking) threatens trait-based inferences drawn from test scores. This "faking-is-bad" (FIB) perspective is being challenged by an emerging "faking-is-good" (FIG) position that condones or favors faking and its underlying attributes (e.g., social skill, ATIC) to the degree they contribute to predictor-criterion correlations and are job relevant. Based on the unitarian model of validity and relevant empirical evidence, we argue the FIG perspective is psychometrically flawed and counterproductive to personality-based selection targeting trait-based fit. Carrying forward both positions leads to variously dark futures for self-report personality tests as selection tools. Projections under FIG, we suggest, are particularly serious. FIB offers a more optimistic future but only to the degree faking can be mitigated. Evidence suggesting increasing applicant faking rates and other alarming trends makes the FIB versus FIG debate a timely if not urgent matter.

Self-report personality tests have become popular selection tools (Ryan et al., 2015). Shadowing empirical support for personality-job performance relationships (e.g., Hogan \& Holland, 2003; Hurtz \& Donovan, 2000; Tett et al., 1999) has been research on the susceptibility of self-report scales to deliberate response distortion or faking. Dozens of studies show that people can fake on personality tests and actually do fake when the stakes are high, as in selection settings (Birkeland et al., 2006; Levashina et al., 2014). An equally important but more fundamental question is how much does faking matter? Two main camps have formed around this question.

The traditional view, based on the unitarian understanding of construct validity (American Educational Research Association, 2014; SIOP, 2018), is that faking undermines the validity of inferences drawn from test scores. Contrasting this "faking is bad" (FIB) perspective, some authors have suggested that "faking is good" (FIG) in the dual sense that it contributes to predictor-criterion correlations, thereby improving validity, and identifies prospectively good employees. ${ }^{1}$ These two perspectives, FIB and FIG, are irreconcilable: Both cannot be true, and moreover, they point to different futures for personality assessment in the workplace.

1 A third perspective-that faking does not matter-aligns with the FIG approach because, like FIG, it suggests steps to reduce or control faking are unwarranted. Faking-is-neutral legitimizes FIG.
Our aim in this paper is to critically examine the FIB and FIG positions in advancing the use of standardized personality tests in selection settings. Conceptual analysis in light of the evidence suggests the FIG approach poses a serious threat to self-report personality assessment for use in hiring. The FIB perspective warns of a similar fate but offers a more promising future targeting improved measurement of job-relevant traits serving more effective personality-based hiring. After clarifying our assumptions and the meaning of faking, we briefly discuss validity as a foun-

Corresponding author:

Robert P. Tett

Email: robert-tett@utulsa.edu

Acknowledgements: We appreciate those who, over the decades, have helped shape our thinking for this paper. First, thanks go to the cohorts of graduate students at The University of Tulsa in the lead author's personnel selection class, who served as resonant sounding boards in developing the ideas presented here. Second, we thank several colleagues whose unique insights on faking and its importance are evident in these pages. Chief among those are Neil D. Christiansen, Richard D. Goffin, Mitch Rothstein, and the late Douglas N. Jackson. Finally, in the nearer term, we appreciate the guidance of the editors of this special issue and two reviewers, who made several key conceptual and empirical contributions in light of the growing faking literature. We thank all those people, but of course any errors, logical or declarative, are entirely ours. 
dation for the FIB versus FIG debate. We then articulate the logic of the two perspectives in light of relevant empirical findings and identify key challenges to the FIG position, particularly with respect to validity. Finally, possible futures for personality tests as selection tools are identified in a conditional defense of the traditional FIB perspective.

\section{Assumptions}

Our arguments build on three assumptions pertaining to, respectively, the personality test user, the test taker, and the test itself. First and foremost, we assume organizations using personality tests in hiring are making a good-faith attempt to distinguish among applicants with respect to their expected fit in meeting work demands. Achieving a good fit benefits both the organization and the worker. Operating from the trait perspective, trait activation theory (Tett \& Burnett, 2003; Tett et al., 2013) suggests fit occurs where workers, by the traits they possess, are rewarded for being themselves, and organizations benefit accordingly by having workers who are trait motivated. From a more strictly empirical standpoint, fit may be promoted using personality tests as self-presentation prediction tools (see below). Ideally, scales used in screening have been identified a priori as job related (SIOP, 2018), but faking is relevant to prediction and fit in both confirmatory and exploratory ventures.

Second, job applicants are assumed to be motivated, to varying degrees, to present an overall favorable impression when completing a self-report personality test. A motivation effect is clearly evident in meta-analyses showing heightened test score means (on positively valued traits) in applicants relative to incumbents (e.g., Jeong et al., 2017; Salgado, 2016), especially on job-relevant scales (Birkeland et al., 2006). The meaning and importance of the motivational shift are near the heart of the FIG/FIB debate, but the shift itself is not in question.

Third, despite the motivational shift, self-report personality tests are assumed to hold potential to yield scores under applicant conditions that permit prediction of important workplace criteria. How well they do that in particular cases depends on a variety of factors (Tett \& Christiansen, 2007), but test scores are generally expected to capture individual differences tied to criterion variance. A key question here is what accounts for correlations between personality test scores and criterion measures. That such prediction is possible, however, is generally not up for debate. ${ }^{2}$

\section{Faking Defined}

Faking on personality tests has been defined in various ways (Holden \& Book, 2012). Building on earlier works (e.g., Zickar et al., 2004), Griffith et al. (2011) identify four types of applicant faking. ${ }^{3}$ Fraudulent faking is deliberate distortion in responding to personality test items opposite what one believes is true about the self. This most extreme form of faking, Griffith et al. suggest, amounts to lying or cheating (see also Tett \& Simonet, 2011). Exaggeration entails intentionally or unintentionally overstating strengths and understating weaknesses, identifiable in most cases as "slight" faking or "polishing the truth." Applicants engaged in reactive responding answer each item to make a favorable impression with regard not to the self but rather to what the applicant expects the organization will find desirable. Finally, deriving from socioanalytic theory (e.g., Johnson \& Hogan, 2006; see also Marcus, 2009), self-presentation is the applicant's attempt to respond to personality items so as to convey the reputation they seek to convey on the job. ${ }^{4}$

All four types of faking are relevant to current aims. The fraudulent form and, to a lesser degree, exaggeration, capture prototypical faking, what most faking researchersand, we suspect, most readers-recognize as challenging to reliance on self-report personality tests in promoting worker-job fit. Those two types of fakers are the marquis players from the FIB perspective, especially the fraudulent variety. Self-presentation is also directly relevant to current discussion, as its conceptual source, socioanalytic theory, is a foundation for the FIG perspective.

The remaining type, reactive faking, is less strategic than the others. Like self-presentation, it does not entail active consideration of what is true about the self, yet it lacks the follow-through in projecting a similar image on the job, critical for prediction based on self-presentation. Reactive fakers are not lying as a deliberate misrepresentation of the perceived self, nor are they polishing the truth. Like other types of fakers, however, their responses to personality test items are keyed to what they think the test user is looking for in a good-fitting candidate. Reactive faking, like other types, thwarts the intentions of the test user and, accordingly, exemplifies the FIB position. The case of self-presentation prompts more detailed evaluation in light of the FIG position, offered in a later section. ${ }^{5}$

Intentionality in faking bears further review for two reasons. First, it has two distinct targets. The first target is the degree to which responses to personality test items are judged in relation to the perceived self. As noted, fraudulent faking is a deliberate misrepresentation of the self, exaggeration may or may not be deliberate in this respect, and reactive faking is definitively unintentional in this sense because the self is not considered. The second target of in-

2 Variability in personality-outcome linkages in applicants is discussed below. For an unusually nihilistic view of self-report personality tests, see Morgeson et al. (2007).

3 Levashina and Campion (2007) offer a similar taxonomy of faking in employment interviews.

4 From a strict socioanalytic viewpoint (Johnson \& Hogan, 2006), faking does not exist because there is no real self against which to judge accuracy in self-report. We adopt Griffith et al.'s perspective in considering self-presentation a type of faking in order to advance comparisons between the FIB and FIG positions.

5 Both reactive responding and self-presentation have respondents choosing answers keyed to making their best impression regardless of the self. The former, however, may abandon impression-making on the job, whereas the latter seeks to garner the same reputation on the job. 
tentionality is the degree to which respondents comply with the good-faith intentions of the test user to identify best-fitting job candidates. Reactive fakers do not deliberately distort responses in light of the perceived self, but they do choose to reject the aim of assessment, which, from a FIB perspective, is to identify test takers' relative standing on stable propensities tied to performance and other outcomes in order to achieve fit. This choice may be driven by norms and coaching to present a favorable impression in applicant settings, but it is a choice nonetheless. The deliberate rejection of the fundamental aim of personality assessment to hire best-fit workers is a critical concern from the FIB perspective, to which we return later in the article.

Intentionality is further relevant to faking to distinguish it from self-deception, the degree to which the respondent perceives the self as more desirable than the true self. Self-deception is unconscious error (Paulhus \& Trapnell, 2008) and, although problematic from a validation standpoint, warrants separate attention (e.g., regarding defense mechanisms and other processes affecting accuracy in self-perception). We do not address self-deception further here, except to assert that unintentional exaggeration, noted above, is more closely aligned with self-deception than with faking.

In light of the foregoing discussion, we adopt Griffith et al.'s (2011) definition of faking as "an intentional response behavior aimed at exerting a positive influence on the hiring decision" (p. 345). Notably, this definition accommodates both self-referenced inaccuracy and more general noncompliance with the primary aim of assessment. It also serves current aims because it identifies the goal of faking, which is to respond to personality test items so as to appear well suited for the job regardless of one's standing on targeted dimensions, and it explicitly recognizes the hiring setting, where motivation to fake is elevated. Faking is most relevant under motivated conditions, which is why it continues to draw attention in selection contexts.

\section{Validity}

Reflecting over 50 years of conceptual refinement (Sireci, 2009), validity is now widely accepted under a "unitarian" model as "the degree to which evidence and theory support the interpretation of test scores proposed by the test user" (American Educational Research Association, 2014, p. 11), with the critical caveat that "The proposed interpretation includes specifying the construct the test is intended to measure." Thus, validity is the degree to which a test measures what it is purported to measure (i.e., a defined construct). Central to the current discussion, specification of a targeted construct rules out a purely empirical rendering of validity, whereby a positive correlation between test $\mathrm{X}$ and criterion Y, by itself, permits "valid" inferences. The unitarian perspective requires in addition that the correlation makes sense in light of the constructs targeted by those measures (Binning \& Barrett, 1989). ${ }^{6}$

Cronbach and Meehl's (1955) seminal contribution to discussions of validity was introduction of the "nomological network" of constructs definitive of and otherwise relating to what the test user understands the test to measure. Support for construct validity comes from the integration of rational argument and various sources of evidence supporting expectations derived from the nomological net. Cronbach and Meehl stated further that, "The problem faced by the investigator is "What constructs account for variance in test performance?"' (p. 282). That validation is about confirming construct-based inferences is imperative for discussion of whether faking on self-report personality tests is bad or good, especially in employment settings.

\section{The "Faking Is Bad" (FIB) Perspective}

The FIB camp, true to the doctrine of construct validity, sees faking as an unwanted source of test score variance. More specifically, it is differential distortion in compliance and/or describing the self relative to what the test taker truly believes, posing a direct threat to construct validity and prediction. Consider a test targeting conscientiousness (C) used to hire wedding consultants. Applicants vary in C, and the test, if construct valid, captures that variance, such that those who see themselves as conscientious score highly and those as lacking in that attribute score low. Because wedding planning requires careful attention to details on several fronts (e.g., scheduling, invitations, menu, budget), it is expected to be performed especially well by conscientious people. So, to the extent the test of $\mathrm{C}$ supports construct-valid inferences, test takers with higher scores will have a higher probability of success on the job.

Faking weakens targeted inferences because, when applicants fake good, they do so to varying degrees, thereby adding variance beyond that attributable to the targeted job-relevant trait (e.g., $\mathrm{C}$ in the case of wedding planner). Sources of faking may include one or more non-targeted variables (e.g., ambition, Machiavellianism, general mental ability; McFarland \& Ryan, 2006; Tett et al., 2012; Tett \& Simonet, 2011). The challenge to construct validity is that the nomological net for the targeted trait (C) may or may not include the factors underlying faking. If it does, those factors may be positively, negatively, or neutrally related to performance and other valued outcomes (Huber et al., 2021; Komar et al., 2008; O'Connell et al., 2011). Regardless of whether or not faking and its attributes contribute to predicting those outcomes, faking as deliberate distortion or noncompliance undermines the inference that scores on the given measure represent persons' standing on the targeted trait (C). That the additional, nontargeted sources of variance can play out independently of targeted sources makes faking, according to this perspective, something worth identifying, assessing, and, as far as possible, constraining.

Critical to note here is that what makes faking bad is

6 We avoid the term "validity coefficient" typically applied to predictor-criterion correlations because a key point in our argument is that inferences of validity require more than mere correlation. 
not simply its attenuation of a correlation between a job-relevant trait measure and a trait-relevant criterion measure. Such an effect is troubling, but the key issue more broadly is construct validity. Correlation is not by itself a sufficient condition for inferring a test is measuring what it is purported to assess. Faking that strengthens the correlation between a personality scale and a criterion measure is equally problematic from the unitarian perspective. We return to this important issue later on.

\section{The "Faking-Is-Good" (FIG) Perspective}

At an intuitive level, the FIG position seems straightforward. Hollenbeck (in Morgeson et al., 2007), for example, claimed that "self-monitoring is probably a good thing in most social contexts, suggesting that whatever contributes to faking may also contribute to job performance" (p. 708). He goes on to note that, "If you work at Disney, you are supposed to be having a good day every single day. Again, if you cannot fake a personality item, how are you going to work at Disney everyday, smiling at these young children stomping on your feet?" (p. 717). Murphy (same article) says:

I am more concerned about the failure to fake. Suppose you are in a situation where you know what you are supposed to do (such as giving a socially desirable or socially acceptable answer) and you cannot or will not do it. We should not be wringing our hands about faking. I think we should be thinking very seriously about the people who give responses that are not socially adaptive in a high stakes situation where they know what they are supposed to do. People who do not know when they should give honest answers and when they should fake might lack a skill of adaptation to a social world. (p. 712)

Dipboye (same article) adds, "Why not start with the reality that applicants obviously will try to convey a favorable image of themselves in a selection situation. If they do not, then that is probably more of a reason for concern than if they do" (p. 713).

More principled grounding for the FIG perspective derives primarily from two overlapping sources: (a) socioanalytic theory (e.g., Hogan \& Blickle, 2013), and (b) self-presentation theory (Marcus, 2009; Marcus et al., 2019). Each theory is described below with an emphasis on its implications regarding the value of faking.

Socioanalytic theory. Hogan and colleagues (e.g., Hogan \& Blickle, 2013; Hogan et al., 1996; Johnson \& Hogan, 2006) argue that people are motivated to pursue status (to get ahead), acceptance (to get along), and personal meaning. The individual's identity is how they want to be seen by others and the individual's reputation is how others actually see them. The testing situation offers the test taker an opportunity to present a chosen identity. Those high on "social skill" create an impression that is consistent with their chosen identity. Carried over to the job, this impression management process yields a reputation consistent with that intended by the individual in responding to personality test items.

According to socioanalytic theory, people are always self-presenting how they want to be seen, whether in completing a personality test or behaving on the job. To test that idea, Hogan et al. (2007) compared mean personality test scores of rejected applicants to mean scores of the same applicants 6 months later under the same conditions and found only trivial increases. They concluded from this that "Our review can be summarized as 'all faking all the time' - which means that faking doesn't matter" (p. 1280). ${ }^{7}$

Two aspects of socioanalytic theory especially relevant to the FIG perspective are (a) an emphasis on empirical prediction over construct validity, and (b) an understanding of faking or the factors that serve it as job relevant. The first feature stems from a rejection of trait theory. Specifically, it is argued there is no reliably known self against which to judge the accuracy of self-report. Faking, accordingly, cannot be understood as a discrepancy between the true self (or even an honestly misperceived self) and one's self-description in responses to personality test items. The term "validity" has special meaning in socioanalytic theory: "item responses are valid when respondents produce scores that correspond to their established social reputations, whether or not their responses correspond literally to actual behaviors and experiences in real life" (Johnson \& Hogan, 2006; p. 214). The primary aim of any assessment, accordingly, is not to assess test takers' standing on a targeted trait but rather to predict on-the-job reputations as evaluated by others. Thus, empirical prediction, not construct validity, is the key aim of assessment.

The second feature of socioanalytic theory with particular relevance to the FIG perspective is that faking is taken to signal a valued test taker characteristic. Hogan and colleagues argue that what translates a person's identity into his or her reputation is social skill. Those skilled in presenting a favorable reputation when completing a personality test will be skilled in creating a similarly favorable reputation on the job. Both test score variance and performance variance thus capture individual differences in social skill, and this is what accounts for empirical covariance between the personality and performance measures. Notably, social skill is not a trait in the stable personality sense of that term but rather is trainable. Of further note, social skill is relevant to all jobs as every work setting offers opportunities to manage impressions favoring one's reputation with respect to valued work behavior (e.g., performance as perceived by

7 In contrast, Hausknecht (2010) and Landers et al. (2011) report sizable increases in personality test scores on retest under applicant conditions. Walmsley and Sackett (2013) suggest Hogan et al's null results may be due to personality scores being given relatively low weight and applicants attending instead to improvements on other tests (e.g., cognitive ability). See Randall and Villado (2017) for a general model of retest effects in work settings. 
one's boss). All personality scales and performance assessments in this light may be considered measures of social skill, although predictor and criterion labels generally do not reflect this as a target of measurement.

This view of personality assessment is clearly at odds with the more prevalent construct validity perspective. Deception (i.e., "faking"), according to socioanalytic theory, "is a conscious, deliberate deviation from typical forms of self-presentation, a deviation that acquaintances would describe as uncharacteristic behavior" (Johnson \& Hogan, 2006; p. 211). Thus, as long as one's responses to personality test items convey the reputation one earns on the job, faking in the construct validity sense as the deviation between one's observed trait score and one's true trait score (or honestly held true score) is entirely moot. "Faking is good" characterizes this perspective because covariance between test and performance measures due to social skill, regardless of accuracy in capturing real trait levels, is what accounts for the predictive relationship: no harm, no foul.

Self-presentation theory. Building on socioanalytic theory, Marcus (2009) suggests, "From the applicant's perspective, attempts to manage the employer's impressions can be understood as an adaptation to situational demands, because obtaining a job offer logically requires making a positive impression on the employer" (p. 418). ${ }^{8}$ Marcus (2006) concludes from partially simulated data that "there appears to be little reason to abandon the use of selection instruments simply because they can be faked, as long as there is evidence of [empirical] validity" (p. 244). Ingold, Kleinmann, König, and Melchers (2015) argue along the same lines that, "as faking was positively related to supervisors' ratings of job performance, the present results diminish concerns...about faking" (p. 430).

Marcus' (2009) self-presentation model proposes two applicant skills in selection settings that boil down to knowing what to say (analytical skill) and knowing how to say it (behavioral skill). The former reflects an ability to identify criteria (ATIC), operationalized as the detection of constructs or performance metrics embedded in selection tools (Griffin, 2014; Kleinmann et al., 2011; Melchers et al., 2012). High ATIC allows one to mind read by accumulating, interpreting, and correctly analyzing ambiguous social cues in adjusting to meet others' expectations. Supporting evidence suggests ATIC (a) predicts hiring decisions and job performance across a variety of methods (Ingold, Kleinmann, König, Melchers, \& Van Iddekinge, 2015; Kleinmann et al., 2011; König et al., 2006; Leugnerova et al., 2016), (b) shows consistency across assessment center exercises with varying performance demands (Speer et al., 2014), and (c) mediates the effects of personality distortion (i.e., ideal employee factor) and performance in high- and low-fidelity work simulations (Klehe et al., 2012). Predictions hold even after controlling for cognitive ability and self-monitoring, suggesting ATIC captures a unique skill in reading the situation as opposed to a general mental capacity or tendency to adjust to social cues (Klehe et al., 2012).
Separately from ATIC, knowing how to present oneself as a desirable job candidate reflects skill in communication, influence, presentation, and stagecraft (Marcus, 2009). Research on this aspect of self-presentation in responding to self-report personality tests is scant. In one study, students high on trait emotional intelligence (EI) improved their odds of attaining different positions by correctly faking personality tests to mirror job demands (Pelt et al., 2018). The authors suggest trait EI captures knowledge not only of what is expected in varied social situations (e.g., home, school, work) but also of how best to respond in a given selection situation. In a related vein, those who faked more on a personality test used more interview impression management tactics and received higher supervisory ratings of job performance (Ingold, Kleinmann, König, \& Melchers, 2015).

Key to present aims, the self-presentation approach to faking, as with socioanalytic theory, evaluates validity in terms of the correlation between a personality scale score and a criterion measure and identifies nontargeted variables (analytic skills, behavioral skills) as legitimate assessment components. As long as a personality scale predicts performance, test users need not be concerned about whether the personality scale captures variables serving faking, independently of the putatively targeted trait.

Having described the FIB and FIG positions, we now consider their implications for the validation of self-report personality tests. Specifically, we show how only the FIB position is consistent with a unitarian understanding of construct validity and that this is of fundamental importance in advancing personality-based selection. Psychometric and other challenges of faking are articulated before possible futures of personality assessment in selection settings are described based on the two perspectives.

\section{Faking and Construct Validity}

A common theme in the workplace faking literature, including studies in both the FIB and FIG camps but advanced more prominently in the latter, is that empirical prediction is the most important aim of assessment. ${ }^{9}$ There is a practical allure to this position: If our goal in screening is to identify applicants most likely to secure high performance ratings, then correlation offers a mechanically efficient guide for making hiring decisions. The critical challenge to this empiricist perspective is that it fails to conform to the established unitarian understanding of validity, which calls for evidence that a given test assesses what it is purported to assess. Prediction offers evidence for validity in the unitarian model only in light of targeted constructs and

8 Marcus suggests faking is just one way to make a favorable impression. Others include frank admissions of one's faults and moderate exaggerations of one's strengths.

9 This generally holds for most of I-O psychology, particularly in more applied domains (e.g., machine learning). Faking offers a tangible target for discussion but key points raised here bear generalization to other areas. 
their theoretical connection. Where a given scale captures nontargeted constructs serving faking (social skill, ATIC, behavioral skill) - even if those variance sources contribute to the correlation-faking compromises construct validity (Huber et al., 2021; Schilling et al., 2021; Tett \& Simonet, 2011). A test putatively targeting conscientiousness (C), from a strictly FIG perspective, need not assess $\mathrm{C}$ at all but rather the ability and willingness to make oneself merely appear well suited to the job. Faking poses a serious challenge to validation in terms of being able to judge how well our measures capture what they are purported to measure.

The pragmatic reader might consider this issue a theoretical "nicety," a technicality reserved for esoteric, ivory tower, armchair rumination. After all, "assessment has a job to do, and the job is to predict nontest performance" (Hogan \& Blickle, 2013; p. 57); so why should it matter whether our tests serve prediction via targeted traits or via a set of attributes underlying faking? There are several good reasons. The first few, described next, relate directly to validation and psychometrics.

First and foremost, faking undermines measurement of targeted traits and contaminates evaluation of that measurement. Faking and the specific attributes serving it may be job relevant, but we need valid measures of $\mathrm{C}$ to the degree variance in $\mathrm{C}$ is meaningfully related to variance in performance (e.g., as a wedding planner) beyond the possible relevance of the ability and willingness to fake high on the $\mathrm{C}$ scale. This is the essence of confirmatory research, based, for example, on personality-oriented work analysis (O’Neill et al., 2013). At best, traits serving faking might offer incremental validity ${ }^{10}$; but, in order to test our trait-based hypotheses, we need to know how well the scale as a measure of the targeted trait predicts relevant outcomes. Faking is problematic even if it contributes to the trait-criterion correlation.

This point bears fleshing out. The claim of socioanalytic theory, that people are essentially faking all the time, offers an unconventional explanation of correlations between personality scales and performance metrics. Those with high "social skill" are said to manage impressions well both in screening and on the job. This could mean actually performing well, but it might also reflect skill in explaining away failure, a knack of performing well only when the boss is looking, or otherwise managing a favorable impression that masks truly suboptimal performance. Softening this a bit, such or similar processes (e.g., involving ATIC) might account for just part of the correlation. Either way, if we seek to interpret the predictor-criterion correlation as evidence bearing on the validity of test-score inferences based on the targeted trait, such alternative interpretations pose a serious threat to those judgments. We should be very concerned if our prospective $\mathrm{C}$ measure correlates positively with wedding planning performance not because of the trait-based rationale but because of correlated error from faking and its underlying attributes operating on both sides of the correlation. The FIG approach acknowledges faking and its sources but ignores their negative impact on construct validation.

Second, along related lines, faking disrupts evaluation of overall testing plans targeting assessment of multiple job-relevant constructs. ${ }^{11}$ If a personality-oriented work analysis identifies conscientiousness $(\mathrm{C})$ as a valued trait in wedding planning and variance on the purported $\mathrm{C}$ measure instead captures variables serving faking, this does not diminish the value of $\mathrm{C}$ as a predictive construct. Rather, the trait goes unmeasured, leaving a gap in coverage of job-relevant qualities. By extension, variables serving faking (e.g., cognitive ability; Christiansen et al., 2021; Davison et al., 2021; Schilling et al., 2021) may be targeted more explicitly elsewhere in the selection battery, rendering faking variance ambiguously redundant. Faking thereby undermines incremental prediction expected from assessment of putatively distinct traits. Whatever the predictive merits of faking might be, the value of the targeted trait goes unrealized.

Third, the FIG perspective, more so than the FIB perspective, promulgates the antiquated view that empirical relationships are sufficient for judgments of validity. The unitarian model makes clear that all of validity is construct validity. Empirical evidence supports validity only to the degree it is consistent with construct-based expectations. By accepting predictor-criterion correlation due to nontargeted factors serving faking as evidence of validity, the FIG approach, whether at an intuitive level (e.g., Morgeson et al., 2007) or more theoretically grounded (e.g., Hogan \& Blickle, 2013; Marcus, 2009), represents a throwback to the days where criterion validity was a "type" of validity as opposed to a source of construct validity evidence. Let's unpack this a bit in the context of personality-performance correlations.

Effects of faking on trait-performance linkages are inconsistent, some studies suggesting little or no effect (Christiansen et al., 1994; Ones et al., 1996; Schmitt \& Oswald, 2006), others showing attenuation due to faking (Anderson et al., 1984; Harold et al., 2003; Hough, 1998; Jeong et al., 2017; Komar et al., 2008; Peterson et al., 2011), and still others showing positive effects (e.g., Huber et al., 2021; Ingold, Kleinmann, König, \& Melchers, 2015; Ingold, Kleinmann, König, Melchers, \& Van Iddekinge, 2015; Marcus et al., 2019). Tull (1998) found that faking correlates positively with sales performance. As faking is a way of selling the self, it is reasonable to consider that attributes serving faking may serve performance in selling other things (see also Ruch \& Ruch, 1967; Spiro \& Weitz, 1990). Watts et al. (2020), conversely, report null effects for impression management on a personality test in relation to retail sales. A purely empirical approach leaves us in the lurch as to why such inconsistencies occur. If we want to

10 On the other hand, faking may decrease incremental validity of personality traits as recently found in Davison et al. (2021) wherein the incremental validity of conscientiousness declined when respondents faked due to enhanced collinearity between conscientiousness and cognitive ability.

11 We thank a reviewer for bringing this point to our attention. 
look beyond sampling error to understand those effects, we need to know not only what attributes underlie faking (e.g., McFarland \& Ryan, 2006) but also the conditions affecting their relevance to targeted criteria (e.g., Komar et al., 2008; Tett \& Simonet, 2011). ${ }^{12}$

Personality scale-performance correlations emerge at the surface of a turbulent sea of processes (e.g., Hauenstein et al., 2017). Only by focusing explicitly on constructs (per construct validation) can an understanding of faking processes be advanced. Where cognitive ability, ATIC, social skill, and other attributes possibly underlying faking (e.g., ambition, job knowledge) are logically tied to performance in particular settings, personality scales susceptible to faking in those respects should, all else being equal, show stronger linkages with performance measures. Regardless of any such predictive gains, however, lumping together targeted and nontargeted variance in touting a stronger correlation as evidence of "validity" ignores, if not undermines, the scientific value of the unitarian view. What we call "criterion validity" is not evidence for validity to the degree it is conferred by nontargeted constructs.

Fourth, extending the previous point, it matters whether prediction is served by a targeted trait (e.g., $\mathrm{C}$ in the job of wedding planner) or by attributes underlying faking (e.g., social skill) because improvements in prediction can be advanced programmatically only by understanding how the parts work independently and as a set. ${ }^{13}$ Construct validation, by promoting evaluation of a measure in terms of a targeted construct, is ultimately a highly practical endeavor. If ATIC, for example, helps explain a correlation between a putative measure of $\mathrm{C}$ and ratings of wedding planning performance, this suggests opportunity to develop separate ATIC measures in considering its relevance to performance in a given job. Assessing it as part of a personality scale targeting $\mathrm{C}$ severely impairs both evaluation of the role of $\mathrm{C}$ in performance from a theoretical standpoint and improvement of the $\mathrm{C}$ measure (explicitly as a measure of $\mathrm{C}$ ) in light of its correlation with relevant criteria.

Fifth, nontargeted attributes serving faking can confound inferences regarding a scale's internal structure. Items sharing susceptibility to faking (and other biases, like self-deception and acquiescence) will yield inflated internal consistency reliability above that expected based on the targeted attribute alone (Heggestad et al., 2006). We should be skeptical of scales marketed for their high reliability estimates to the degree their items are saturated with faking variance. Basically, the glue providing consistency is not only what the scale's label suggests. This point extends to external structure as well per the ideal employee factor reported by some under applicant conditions (Christiansen et al., 2021; Holden \& Book, 2012; Huber et al., 2021; Schermer et al., 2019; Schmit \& Ryan, 1993; see also Bradley \& Hauenstein, 2006). Differential susceptibility to faking impedes cross-scale comparisons on key psychometric properties.

In sum, the FIG approach is problematic from a vali- dation standpoint because it (a) uncritically accepts faking in confounding evaluation of trait measures based on traits as constructs; (b) undermines evaluation of multiconstruct testing plans, generating unspecified redundancies and gaps in coverage of job-relevant traits; (c) promulgates the antiquated view that correlation is a sufficient condition for validity; (d) fosters continued reliance on fakable trait measures rather than directing efforts to improve assessment of job-relevant traits; and (e) ignores effects of faking on personality scale structure, both internal and external. Beyond those largely psychometric concerns, faking poses a variety of other challenges in selection settings.

\section{Other Challenges of Faking}

Faking opportunity is determined by one's honestly held standing on a trait (McFarland \& Ryan, 2006; Tett \& Simonet, 2011; Tett et al., 2012). Those with the greatest opportunity to fake upward on a positively valued dimension are those who honestly see themselves as falling at the low end of that dimension (Peterson et al., 2011). The biggest fakers, accordingly, are likely to be opposite those the organization is looking for in an ideal candidate in terms of personality (Tett \& Christiansen, 2007). This is detrimental to both the organization and the applicant. Even if faking affords useful prediction of performance, it cannot engender job satisfaction from trait-based PE fit (Charbonneau et al., in press); good fit accrues to the degree the individual's traits help meet work demands (Christiansen et al., 2014; Tett et al., 2013). Faking essentially guarantees poor fit over time in terms of trait-based satisfaction, promising weaker work motivation and higher withdrawal.

The cross-situational consistency of personality, expected by most personality test users under a traditional trait assumption, means those willing and able to fake in the screening situation will be willing and able to fake on the job (e.g., getting away with calling in sick as a pretense to play golf). ${ }^{14}$ Consistent with this expectation, Peterson et al. (2011) found that faking on a $\mathrm{C}$ scale correlates positively with counterproductive work behaviors (CWBs). Similar results are reported by Hakstian and $\mathrm{Ng}$ (2005) and by Rosse et al. (1999). This directly supports the FIB perspective. It also bears consideration in terms of construct validity: It makes sense that faking, as a form of deviance, is positively related to deviant behavior on the job. By extension, fleshing out the nomological network of attributes

12 Levashina (2018) and Tett and Christiansen (2007) explicitly consider the research on the predictive merits of faking (see also Burns \& Christiansen, 2006, regarding reliance on social desirability scales as faking measures). Our aims here, in contrast, are to advance the merits of a construct approach to validation in promoting reliance on personality tests as selection tools.

13 We can predict with $100 \%$ certainty that the sun will "rise" in the east on any given morning, but getting people to Mars and back requires knowing what revolves around what.

14 Roulin and Bourdage (2017) offer similar reasoning involving deceptive tactics in employment interviews. 
underlying faking promises more precise explication of the faking-CWB relationship.

Hiring fakers not only increases the risk of lower performance and higher deviance, it also bumps out better fitting candidates from the hiring competition. Griffith et al. (2007) found that some successful applicants scoring high on a $\mathrm{C}$ measure scored lower on retesting 6 months posthire. Further analyses showed that relying on the posthire scores, presumed to be more honest, would have resulted in substantially different hiring decisions. Mueller-Hanson et al. (2003) and Donovan et al. (2014) report similar results. The loss of better fitting candidates is compounded if the false negatives are hired by competitors.

Regardless of its practical implications, faking is an affront to the golden rule. Organizations using personality tests for hiring are making a good faith attempt to identify best-fitting applicants under an implicit contract (i.e., "You tell us who you are and we will hire you if you fit the job"). Condoning faking, per the FIG approach, weakens the moral foundation of that exchange. By the same token, if faking is acceptable, applicants should be informed that we want them to describe themselves, not as they see themselves but rather as what they think we are looking for in a good candidate. Otherwise, we are penalizing honesty (Griffin \& Wilson, 2012) and compliance.

Extending the previous point, hiring fakers can be expected, over time, to weaken the organization's moral compass. ${ }^{15}$ Hannah and Jennings (2013) discuss how ethical character ("ethos") is critical for a leader's ability to influence others and how such character is nurtured by the shared ethics of organizational members. van Blijswijk et al. (2004) discuss integrity as the foundation of trust in government, and others have shown how ethical leaders prevent institutional decay by exemplifying integrity and social responsibility to inspire dedication, sacrifice, and cooperation to achieve greater goods (De Hoogh \& Den Hartog, 2008; Lawton \& Páez, 2015). Organizations ignoring faking face increased demand for ethical stewardship to offset hiring of workers with noncompliant and deceitful proclivities.

Two final points: Faking can promote negative reactions toward personality tests, especially in more honest applicants (Honkaniemi et al., 2011), and, to the degree GMA underlies faking ability (Christiansen et al., 2021; Davison et al., 2021; Schilling et al., 2021; Tett et al., 2012), tests susceptible to faking are more likely to yield adverse impact, increasing legal exposure.

\section{Possible Futures for Self-Report Personality Tests as Se- lection Tools}

The foregoing discussion points to different futures for self-report personality assessment in the workplace depending on whether one adopts a FIB or FIG perspective. The former, grounded in the unitarian model of construct

15 We thank Rick Goffin for bringing this implication to our attention. validity, offers gains in the utility of personality tests through efforts to reduce or otherwise manage faking. The latter approach, which condones or promotes faking from an empiricist standpoint, promises a more deeply troublesome future. Specifically, we assert proliferation of the FIG perspective will lead ultimately to the demise of self-report personality assessment in hiring settings. This may seem hyperbolic, perhaps melodramatic. The stakes, however, are high, and what follows, in the very least, provides a framework for extended didactic discourse. Let us carry forward first the logic of the FIG position.

The future from the FIG perspective. Earlier, we identified two key features of the FIG approach: An emphasis on predictive utility over construct validity and the suggestion that faking and the qualities serving it (e.g., social skill, ATIC) may be job relevant. Here, we delve deeper into the FIG position as a selection paradigm by identifying three distinct hurdles applicants must overcome to be hired. Implicit in the FIG view, successful job candidates are those who (a) recognize that faking is the correct strategy when completing a personality test as a job applicant, (b) choose to fake, and (c) fake well (i.e., so as to appear truly suitable for the job). Each step in this process offers opportunity for distinguishing among applicants. As with true hurdles, these three work only when there is variance in getting over them.

The first hurdle (i.e., recognizing faking as appropriate) works only when at least some applicants believe the test targets honestly held beliefs about the self. Otherwise, recognizing that faking is the correct strategy offers no competitive advantage. The successful applicant, like a player in a social game (Johnson \& Hogan, 2006; Marcus et al., 2019), is one who sees it when others do not. The question then becomes, how likely is it that this hurdle will remain active? Something of a paradox arises in considering this question. As the FIG perspective takes hold, and increasing numbers of applicants come to see faking as the correct strategy in completing self-report personality tests, fewer and fewer traditional (honest) applicants will remain against whom the choice to fake is advantageous. Accordingly, in order to keep this hurdle operative in selection, it must be kept in the shadows.

Yet, as the FIG position spreads, it can only be a matter of time before the first hurdle is widely exposed: At some point, sooner or later, all applicants can be expected to identify faking as the appropriate strategy for personality test completion (Bangerter et al., 2012). How quickly this occurs will depend on the success of efforts to keep the proposed value of faking under wraps (see below). The challenge, then, is to defend the case for faking but without revealing to the majority of test takers that faking is a legitimate strategy to getting hired.

The second hurdle in the FIG strategy is that, once faking is recognized as the appropriate way to complete a self-report test, the applicant must choose to fake. This hurdle is very closely situated to the first. Even if fully aware 
that faking is the norm and that fakers tend to get hired, an applicant might nonetheless choose not to fake. One such individual would be someone who perceives their actual traits to be well aligned with job demands, eliminating not only the need to fake but also the opportunity to do so (Tett \& Simonet, 2011; Tett et al., 2012). Those who perceive their actual trait levels are not so well aligned: however, who still choose not to fake, despite being fully aware of pro-faking norms and outcomes, are likely to be in a very small minority. The reasons are obvious. People apply for jobs because they seek employment. Avoiding faking under the specified conditions would be a deliberate act of self-sabotage, akin to intentionally arriving late and unkempt for a job interview or purposely insulting the interviewer. Such people are out there, to be sure; but serious applicants in the normal range of functioning can be expected to be sensitive to norms, especially when the stakes are high, as in employment situations. Thus, to the degree faking is widely acknowledged to be a viable test-taking strategy in screening, it is reasonable to assume the large majority of applicants will choose to fake if they judge their trait levels unfit for the job. Accordingly, the second hurdle offering a means to distinguish among job applicants in the FIG model falls pretty much in unison with the unveiling of the first hurdle, making faking a widely accepted and essentially universal practice.

Note that the story has unfolded to this point without engaging ethical and other initiatives raised above. For example, the hiring organization might, for the sake of fairness, choose to inform all applicants that faking is not only expected but also required of candidates. This directive could also be justified in seeking more homogeneous and interpretable data. Regardless of how the first two hurdles are removed, the FIG perspective, we suggest, leads inevitably to their removal. This leaves only the third hurdle, which is knowing how to respond to personality test items so as to make oneself appear most suited to the given job.

There is general consensus that faking well (as opposed to faking per se) is a cognitively demanding task (Christiansen et al., 2021; Davison et al., 2021; Levashina et al., 2009; Schilling et al., 2021; Vasilopoulos \& Cucina, 2006). Not all who fake do so in a way that improves their chances of being hired. Some fail to recognize job-relevant items, others choose the wrong end of the response continuum (e.g., agree/disagree), still others fake consistently to one extreme or the other, failing to appreciate that, at least for some traits (and/or items), the ideal score is in the middle of the scale. Applicants able to successfully navigate the test landscape to present themselves as high-fit candidates demonstrate at least a working understanding of the job and how specific items relate to key job demands (e.g., ATIC). The FIG logic on this point seems tight enough: Hiring high-scoring fakers promises to be effective because people who know the job and what it takes to be good at it can generally be expected to perform that job well. But let's examine that assumption a little more closely.
What does it take to know a job and answer job-relevant items correctly? Experience helps, especially in similar jobs. General cognitive ability aids in both the retention and retrieval of job-related experience, and it should help further with identifying job-relevant items and response options. Consistent with this, Schilling et al. (2021) report meta-analytic mean correlations between cognitive ability and personality test scores that are stronger in selection settings (mean rho $=.11$ to .26 ) than in nonselection settings (.00 to .16). Similarly, Christiansen et al. (2021) found cognitive ability to account for both a mean shift in personality scores and a stronger general personality factor, indicative of faking, in applicants compared to incumbents. Interest in the job might also serve faking, to the degree schema are better developed on topics we find interesting (Ackerman, 1996). Social skill and ATIC, as noted above, may be key sources of successful faking. Knowing the job by way of experience, general ability, and interest is clearly relevant to job performance, and social skill and ATIC are further relevant to most if not all jobs. All this is well within the comfort zone of those pursuing a FIG strategy. Two important caveats, however, bear consideration.

The first caveat is that job knowledge (however achieved) is far more directly assessable by way of a test explicitly developed to assess that knowledge (e.g., using a situational judgment test) than indirectly by way of a personality test. Similarly, job experience, general ability, and work interests permit more direct, unambiguous, and logically defensible assessment than by way of a personality test. ATIC and social skill also seem likely to be better assessed if explicitly targeted at the outset of scale development (e.g., as emotional intelligence, Pelt et al., 2018; or self-presentation skill, Marcus et al., 2019). Here is the key point: If the KSAs tied to successful faking on a personality test become the true targets of measurement, then why bother with personality testing at all? Why not "cut out the middle man" and go more directly to the sources of faking variance judged to be job relevant?

The second caveat is that, by implicitly (or even explicitly) targeting job knowledge, experience, ability, interest, social skill, and/or ATIC, we do not really have a personality test at all but rather a messy compound scale that is simply mislabeled as a "personality test." This has serious implications for construct validity, as noted above, but it also points directly to the demise of self-report personality testing in the normal sense of that term.

Putting all this together, a reasonable expectation carrying forward the FIG argument-that faking is a good way to distinguish good from poor workers or, in its weaker variant, does not matter-is that personality tests are doomed for extinction as selection tools. If faking is desirable or condoned, then eventually all applicants will realize this and all but a few with unsuitable traits will choose to fake for both normative and practically competitive reasons. When they do, those who fake well will be hired, but the same KSAs serving successful faking (prior work ex- 
perience, $g$, interests, social skill, ATIC) are better assessed more directly without traditional self-report personality tests. If we continue to rely on those tests regardless (because they correlate with performance), they are by that point not assessing personality traits.

Other reasons, noted earlier, dig the grave deeper: The biggest fakers are opposite those at the desirable end of job-relevant traits; good fakers can be expected to be effective deceivers on the job, so hiring them is risky both in the short term (e.g., increased CWBs) and over time in undermining the organization's moral compass; satisfaction-based fit, conferred by having personality traits that truly match key work demands, can be expected to be poor. In light of all those issues, organizations will understandably switch to devices that are harder to fake (Bangerter et al., 2012), seeking to invest their selection dollars in tools promising higher returns.

The doom-and-gloom future of the FIG strategy contrasts with possible futures afforded by the more traditional FIB perspective but only conditionally. It is to those futures that we now turn.

The future from the FIB perspective. Relative to the FIG path, the way forward from a FIB perspective is less certain. One possibility is that faking may prove too strong to be contained: too easy to do and too hard to control (especially given justifications promulgated by the FIG position). If so, the end may be the same as that befalling the FIG perspective, but the trail is different. Rather than having key hurdles rendered inert and personality tests replaced by other measures more explicitly targeting job-relevant faking attributes, death by faking occurs in the FIB camp from contamination of construct-driven, trait-relevant variance by unwanted error variance with differential job relevance. In short, FIG leads to the demise of self-report personality tests by the loss of variance producers (i.e., the three noted hurdles), whereas failing to limit faking, according to the FIB view, threatens personality assessment by measurement contamination.

Alternatively, the FIB view also offers a more promising path forward, one supporting personality test use in hiring afforded in part by success in identifying and controlling faking as an unwanted source of variance. This more optimistic possibility is that self-report tests can be developed that are relatively immune to faking, whether by careful wording to avoid reliance on especially value-laden terms, by instructions designed to promote truthful self-description (e.g., reasonable threats of faking detection), by forcing respondents to choose between self-descriptions paired on desirability, by inclusion of impossible virtues (e.g., being skilled in fictitious domains), by situating items in explicitly work-related settings (i.e., "at work"), and similar means. Research streams exist on each of those fronts, offering promise along those lines (see Levashina, 2018; Tett et al., 2006).

Further on the plus side, the FIB perspective is not at odds with the appropriateness of faking as a source of variance (i.e., hurdle 1). Rather, everything is pretty much out in the open. Applicants are explicitly discouraged from faking. Fairness is a goal of assessment for ethical as well as practical reasons, tied to both applicant reactions (level playing field) and decision validity (unbiased decisions). The constructs actually targeted for assessment are those for which the scales are labeled (e.g., a "C" test targets $\mathrm{C}$, not the ability and willingness to fake high on $\mathrm{C}$ ), and construct validity remains the gold standard of psychometric quality, as it is in most domains of psychological inquiry.

Perhaps an overly idealistic prospect coming out of the FIB approach is that applicants might more universally come to realize that faking is ultimately self-defeating in that it promotes a poor fit to the job from a personality standpoint (Charbonneau et al., in press). A good-fitting job is one offering opportunities at multiple levels (e.g., task, group, and organization) for workers to express themselves in ways that are positively valued by the organization (Tett \& Burnett, 2003; Tett et al., 2013). Weighing against this ideal is the fact that people are generally motivated to gain employment and associated rewards in the form of pay, benefits, and status. Putting a roof over one's head, food on the table, and extra money in one's pocket typically supersede the pleasantries of a comfortable personality-based fit at work. For able applicants, however, especially in a strong economy where jobs are plentiful, a reasonable goal should be to land a job that is especially well suited to one's particular traits. In such times of plenty, faking promises more pain than gain to the applicant in terms of fit. Indeed, Charbonneau et al. (in press) report deceptive impression management in job interviews is negatively related to perceived fit at the job and organization levels. Advocates of the construct approach to personality assessment might accordingly help applicants and hiring organizations achieve a better fit by promoting honest and accurate self-reporting of job-relevant personality traits.

\section{Summary and Conclusions}

Personality has much to offer as a basis for hiring goodfit workers. The traditional logic, tracing back to the origins of personality testing, is that (a) people differ in stable propensities to behave (i.e., traits), (b) some traits are meaningfully and reliably linked to performance in a given job, and (c) self-report offers a convenient, albeit imperfect, way to assess individual differences in job-relevant traits. Thus, (d) hiring those scoring high on positively valued, job-relevant traits is expected to increase mean performance levels, worker satisfaction, and organizational success.

Faking is a problem in the traditional model because it threatens the third part of the logic: High scores can indicate either high standing on a job-relevant trait or the ability and willingness to make oneself merely appear to have that high standing. Distinguishing those two cases is the crux of the faking problem in selection settings. In contrast to the FIG perspective, which discounts faking in pursuit of raw predictive power, the FIB approach seeks to minimize it as 
a threat to construct validity, thereby improving personality-based selection.

The demise of personality assessment by either route is far from certain, but we see it as a very real possibility should applicants reach a tipping point in the proportion who fake. Experimental work on social change shows adoption of a new norm by only $25 \%$ of group members can spark an abrupt shift in prevailing practice (Centola et al., 2018). Organizational estimates of faking prevalence of around 14\% in the 1960s (Dunnette et al., 1962) have grown to $30 \%$ and even $62 \%$ more recently (Donovan et al., 2003; Griffith et al., 2007; see Levashina, 2018). To the extent this corresponds to increasing beliefs that faking is common, favorable, and doable, a rise in actual faking behavior seems likely (McFarland \& Ryan, 2006), promoting an arms race pitting applicant self-presentation tactics against organizational needs for valid signals (Bangerter et al., 2012). Such increases in faking are troubling as completing self-report measures is susceptible to coaching (Alliger \& Dwight, 2000), and simulations show it takes only $30 \%$ of applicants who fake to a larger degree (1.5 theta shift) to severely compromise the construct validity of personality tests (Lee et al., 2019).

Supporting our concern is recent direct evidence that personality tests are less predictive of performance when based on applicant samples, where the motivation to fake is heightened. Jeong et al. (2017) compared personalityperformance correlations for incumbents versus hired applicants in four samples. In all four cases, linkages were weaker for applicants (mean $=.08$, range $=.01$ to .19 ) than for incumbents (mean $=.28$, range $=.23$ to .44$)$. The overall weakness of the applicant-based results undermines expectations of empirical gains from faking. Published validation studies using applicants are relatively rare, and more such studies are needed going forward. It is reasonable to ask, however, whether we are currently witnessing the fall of personality assessment for use in hiring, as discussed above.

The trends, if true, suggest the need for action. In light of the arguments presented here, we urge researchers and those relying on standardized personality tests for personnel selection to weigh carefully the implications of allowing faking and its underlying attributes to contaminate targeted trait variance, to resist the lure of a correlation strengthened by nontargeted constructs, and to seek improvements in personality assessment through application of the unitarian understanding of validity. In particular, there is an ongoing need to develop more faking-resistant self-report measures whether regarding item format (e.g., forced choice), response instructions (e.g., warnings) or, otherwise, improvements in faking detection methods.

Along related lines, we urge personality test publishers to more routinely validate their predictive inferences based on applicants (Jeong et al., 2017) and urge organizations to weigh such evidence in judging whether or not to use a personality test in hiring. We further recommend that organizations using personality tests in hiring should emphasize to applicants the value of honest responding and compliance with good-faith efforts to achieve a good fit with the work setting. Adopting a FIG perspective threatens to delegitimize personality assessment in selection efforts. Constructs and the accuracy of their assessment matter, and whatever may be good about applicant faking is bad for personnel selection based on job-relevant personality traits.

\section{REFERENCES}

Ackerman, P. L. (1996). A theory of adult intellectual development: Process, personality, interests, and knowledge. Intelligence, 22(2), 227-257.

Alliger, G. M., \& Dwight, S. A. (2000). A meta-analytic investigation of the susceptibility of integrity tests to faking and coaching. Educational and Psychological Measurement, 60(1), 59-72.

American Educational Research Association, American Psychological Association, \& National Council on Measurement in Education. (2014). Standards for educational and psychological testing (4th ed.). American Educational Research Association.

Anderson, C. D., Warner, J. L., \& Spencer, C. C. (1984). Inflation bias in self-assessment examinations: Implications for valid employee selection. Journal of Applied Psychology, 69, 574-580.

Bangerter, A., Roulin, N., \& König, C. J. (2012). Personnel selection as a signaling game. Journal of Applied Psychology, 97(4), 719-738.

Binning, J. F., \& Barrett, G. V. (1989). Validity of personnel decisions: A conceptual analysis of the inferential and evidential bases. Journal of Applied Psychology, 74(3), 478-494.

Birkeland, S. A., Manson, T. M., Kisamore, J. L., Brannick, M. T., \& Smith, M. A. (2006). A meta-analytic investigation of job applicant faking on personality measures. International Journal of Selection and Assessment, 14(4), 317-335.

Bradley, K. M., \& Hauenstein, N. M. (2006). The moderating effects of sample type as evidence of the effects of faking on personality scale correlations and factor structure. Psychology Science, 48(3), 313-335.

Burns, G. N., \& Christiansen, N. D. (2006). Sensitive or senseless: On the use of social desirability measures in selection and assessment. In R. L. Griffith \& M. H. Peterson (Eds.), A closer examination of applicant faking behavior (pp. 115-150). Information Age.

Centola, D., Becker, J., Brackbill, D., \& Baronchelli, A. (2018). Experimental evidence for tipping points in social convention. Science, 360(6393), 1116-1119.

Charbonneau, B. D., Powell, D. M., Spence, J. R., \& Lyons, S. T. (in press). Unintended consequences of interview faking: Impact on perceived fit and affective outcomes. Personnel Assessment and Decisions.

Christiansen, N. D., Goffin, R. D., Johnston, N. G., \& Rothstein, M. G. (1994). Correcting the 16PF for faking: Effects on criterion-related validity and individual hiring decisions. Personnel Psychology, 47(4), 847-860.

Christiansen, N. D., Robie, C., Burns, G. N., Loy, R. W., Speer, A. B., \& Jacobs, R. R. (2021). Effects of applicant response distortion on the relationship between personality trait scores 
and cognitive ability. Personality and Individual Differences $171,110542$.

Christiansen, N. C., Sliter, M., \& Frost, C. T. (2014). What employees dislike about their jobs: relationship between personality-based fit and work satisfaction. Personality and Individual Differences, 71, 25-29.

Cronbach, L. J., \& Meehl, P. E. (1955). Construct validity in psychological tests. Psychological Bulletin, 52(4), 281-302.

Davison, H. K., Kluemper, D. H., Tao, S., Stewart, D. W., \& Bing, D. (2021). The effects of faking on the relationship between cognitive ability and conscientiousness: A cautionary note. International Journal of Selection and Assessment. Advance online publication. https://doi.org/10.1111/ijsa.12319

De Hoogh, A. H., \& Den Hartog, D. N. (2008). Ethical and despotic leadership, relationships with leader's social responsibility, top management team effectiveness and subordinates' optimism: A multi-method study. Leadership Quarterly, 19(3), 297-311.

Donovan, J. J., Dwight, S. A., \& Hurtz, G. M. (2003). An assessment of the prevalence, severity, and verifiability of entry-level applicant faking using the randomized response technique. Human Performance, 16(1), 81-106.

Donovan, J. J., Dwight, S. A., \& Schneider, D. (2014). The impact of applicant faking on selection measures, hiring decisions, and employee performance. Journal of Business and Psychology, 29, 479-493.

Dunnette, M. D., McCartney, J., Carlson, H. C., \& Kirchner, W. K. (1962). A study of faking behavior on a forced-choice self-description checklist. Personnel Psychology, 15, 13-24.

Griffin, B. (2014). The ability to identify criteria: Its relationship with social understanding, preparation, and impression management in affecting predictor performance in a highstakes selection context. Human Performance, 27(2), 147164.

Griffin, B., \& Wilson, I. G. (2012). Faking good: self-enhancement in medical school applicants. Medical Education, 46(5), 485-490.

Griffith, R. L., Chmielowski, T., \& Yoshita, Y. (2007). Do applicants fake? An examination of the frequency of applicant faking behavior. Personnel Review, 36(3), 341-355.

Griffith, R. L., Lee, L. M., Peterson, M. H., \& Zickar, M. J. (2011). First dates and little white lies: A trait contract classification theory of applicant faking behavior. Human Performance, 24(4), 338-357.

Hakstian, A. R., \& Ng, E. (2005). Employment related motivated distortion: Its nature, measurement, and reduction. Educational and Psychological Measurement, 65, 405-441.

Hannah, S. T., \& Jennings, P. L. (2013). Leader ethos and Big-C character. Organizational Dynamics, 42(1), 8-16.

Harold, C. M., McFarland, L. A., \& Weekley, J. A. (2003, April). The validity of verifiable and nonverifiable biodata items: An examination across applicants and incumbents. Paper presented at the 18th Annual Conference of the Society for Industrial and Organizational Psychology, Orlando, FL.

Hauenstein, N. M. A., Bradley, K. M., O'Shea, P. G., Shah, Y. J., \& Magill, D. P. (2017). Interactions between motivation to fake and personality item characteristics: Clarifying the process. Organizational Behavior and Human Decision Processes, $138,74-92$.
Hausknecht, J. P. (2010). Candidate persistence and personality test practice effects: Implications for staffing system management. Personnel Psychology, 63, 299-324.

Heggestad, E. D., George, E., \& Reeve, C. L. (2006). Transient error in personality scores: Considering honest and faked responses. Personality and Individual Differences, 40, 12011211.

Holden, R. R., \& Book, A. S. (2012). Faking does distort self-report personality assessment. In M. Ziegler, C. MacCann, \& R. D. Roberts (Eds.), New perspectives on faking in personality assessment (pp. 71-84). Oxford University Press.

Hogan, J., Barrett, P., \& Hogan, R. (2007). Personality measurement, faking, and employment selection. Journal of Applied Psychology, 92(5), 1270-1285.

Hogan, J., \& Holland, B. (2003). Using theory to evaluate personality and job-performance relations: A socioanalytic perspective. Journal of Applied Psychology, 88(1), 100-112.

Hogan, R., \& Blickle, G. (2013). Socioanalytic theory. In N. D. Christiansen \& R. P. Tett (Eds.), Handbook of personality at work. Routledge.

Hogan, R., Hogan, J., \& Roberts, B. W. (1996). Personality measurement and employment decisions: Questions and answers. American Psychologist, 51(5), 469-477.

Honkaniemi, L., Tolvanen, A., \& Feldt, T. (2011). Applicant reactions and faking in real-life personnel selection. Scandinavian Journal of Psychology, 52(4), 376-381.

Hough, L. M. (1998). Effects of intentional distortion in personality measurement and evaluation of suggested palliatives. Human Performance, 11, 209-244.

Huber, C. R., Kuncel, N. R., Huber, K. B., \& Boyce, A. S. (2021). Faking and the validity of personality tests: An experimental investigation using modern forced choice measures. Personnel Assessment and Decisions, 7(1), 20-30.

Hurtz, G. M., \& Donovan, J. J. (2000). Personality and job performance: The Big Five revisited. Journal of Applied Psychology, 85(6), 869-879.

Ingold, P. V., Kleinmann, M., König, C. J., \& Melchers, K. G. (2015). Shall we continue or stop disapproving of self-presentation? Evidence on impression management and faking in a selection context and their relation to job performance. European Journal of Work and Organizational Psychology, 24(3), 420-432.

Ingold, P. V., Kleinmann, M., König, C. J., Melchers, K. G., \& Van Iddekinge, C. H. (2015). Why do situational interviews predict job performance? The role of interviewees' ability to identify criteria. Journal of Business and Psychology, 30(2), 387-398.

Jeong, Y. R., Christiansen, N. D., Robie, C., Kung, M. C., \& Kinney, T. B. (2017). Comparing applicants and incumbents: Effects of response distortion on mean scores and validity of personality measures. International Journal of Selection and Assessment, 25(3), 311-315.

Johnson, J. A., \& Hogan, R. (2006). A socioanalytic view of faking. In R. L. Griffith \& M. H. Peterson (Eds.), A closer examination of applicant faking behavior (pp. 209-231). Information Age.

Klehe, U. C., Kleinmann, M., Hartstein, T., Melchers, K. G., König, C. J., Heslin, P. A., \& Lievens, F. (2012). Responding to personality tests in a selection context: The role of the ability to identify criteria and the ideal-employee factor. Human Performance, 25(4), 273-302. 
Kleinmann, M., Ingold, P. V., Lievens, F., Jansen, A., Melchers, K. G., \& König, C. J. (2011). A different look at why selection procedures work: The role of candidates' ability to identify criteria. Organizational Psychology Review, 1(2), 128-146.

Komar, S., Brown, D. J., Komar, J. A., \& Robie, C. (2008). Faking and the validity of conscientiousness: A Monte-Carlo investigation. Journal of Applied Psychology, 93, 140-154.

König, C. J., Melchers, K. G., Kleinmann, M., Richter, G. M., \& Klehe, U. C. (2006). The relationship between the ability to identify evaluation criteria and integrity test scores. Psychology Science, 48(3), 369-377.

Landers, R. N., Sackett, P. R., \& Tuzinski, K. A. (2011). Retesting after initial failure, coaching rumors, and warnings against faking in the use of personality measures for selection. Journal of Applied Psychology, 96, 202-210.

Lawton, A., \& Páez, I. (2015). Developing a framework for ethical leadership. Journal of Business Ethics, 130(3), 639-649.

Lee, P., Joo, S.-H., \& Fyffe, S. (2019). Investigating faking effects on the construct validity through the Monte Carlo simulation study. Personality and Individual Differences, 150, 109491

Leugnerova, M., Vaculik, M., \& Prochazka, J. (2016). The influence of candidate social effectiveness on assessment center performance ratings: A field study. International Journal of Selection and Assessment, 24(2), 1507-160.

Levashina, J. (2018). Evaluating deceptive impression management for personnel selection and job performance. In R. Rogers \& S. D. Bender (Eds.), Clinical Assessment of Malingering and Deception (4th Edition, pp. 530-551). The Guilford Press.

Levashina, J., \& Campion, M. A. (2007). Measuring faking in the employment interview: Development and validation of an interview faking behavior scale. Journal of Applied Psychology, 92, 1638-1656.

Levashina, J., Morgeson, F. P., \& Campion, M. A. (2009). They don't do it often, but they do it well: Exploring the relationship between applicant mental abilities and faking. International Journal of Selection and Assessment, 17(3), 271-281.

Levashina, J., Weekley, J. A., Roulin, N., \& Hauck, E. (2014). Blatant extreme responding in high-stakes selection. International Journal of Selection and Assessment, 22, 371-383.

Marcus, B. (2006) Relationships between faking, validity, and decision criteria in personnel selection. Psychology Science, $48,226-246$.

Marcus, B. (2009). "Faking" from the applicant's perspective: A theory of self-presentation in personnel selection settings. International Journal of Selection and Assessment, 14, 417430.

Marcus, B., Goldenberg, J., Fine, S., Hummert, H., \& Traum, A. (2019). Self-presentation in selection settings: The case of personality tests. Journal of Business and Psychology, 35, 557-571.

McFarland, L. A., \& Ryan, A. M. (2006). Toward an integrated model of applicant faking behavior. Journal of Applied Social Psychology, 36, 979-1016.

Melchers, K. G., Bösser, D., Hartstein, T., \& Kleinmann, M. (2012). Assessment of situational demands in a selection interview: Reflective style or sensitivity?. International Journal of Selection and Assessment, 20(4), 475-485.

Morgeson, F. P., Campion, M. A., Dipboye, R. L., Hollenbeck, J.
R., Murphy, K., \& Schmitt, N. (2007). Reconsidering use of personality tests in personnel selection contexts. Personnel Psychology, 60, 683-729.

Mueller-Hanson R., Heggestad, E. D., \& Thornton, G. C. (2003). Faking and selection: Considering the use of personality from the select-in and select-out perspectives. Journal of Applied Psychology, 88, 348-355.

O'Connell, M. S., Kung, M., \& Tristan, E. (2011). Beyond impression management: Evaluating three measures of response distortion and their relationship to job performance. International Journal of Selection and Assessment, 19, 340-351.

O'Neill, T. A., Goffin, R. D., \& Rothstein, M. (2013). Personality and the need for personality-oriented work analysis. In R. P. Tett \& N. Christiansen (Eds.), Handbook of personality at work (pp. 226-252). Routledge.

Ones, D. S., Viswesvaran, C., \& Reiss, A. D. (1996). Role of social desirability in personality testing for personnel selection: The red herring. Journal of Applied Psychology, 81, 660679.

Paulhus, D. L., \& Trapnell, P. D. (2008). Self-presentation of personality: An agency-communion framework. In O. P. John, R. W. Robins, \& L. A. Pervin (Eds.), Handbook of personality psychology: Theory and research (pp. 492-517, 3rd ed.). Guilford Press.

Pelt, D. H., van der Linden, D., \& Born, M. P. (2018). How emotional intelligence might get you the job: The relationship between trait emotional intelligence and faking on personality tests. Human Performance, 31(1), 33-54.

Peterson, M. H., Griffith, R. L., Isaacson, J. A., O'Connell, M. S., \& Mangos, P. M. (2011). Applicant faking, social desirability, and the prediction of counterproductive work behaviors. Human Performance, 24(3), 270-290.

Randall, J. G., \& Villado, A. J. (2017). Take two: Sources and deterrents of score change in employment retesting. Human Resource Management Review, 27(3), 536-553.

Rosse, J. G., Levin, R. A., \& Nowicki, M. D. (1999, April). Assessing the impact of faking on job performance and counterproductive job behaviors. In P. Sackett (Chair), New empirical research on social desirability in personality measurement. Symposium conducted at the 14th Annual Conference of the Society of Industrial Organizational Psychology, Atlanta, $\mathrm{GA}$.

Roulin, N., \& Bourdage, J. S. (2017). Once an impression manager, always an impression manager? Antecedents of honest and deceptive impression management use and variability across multiple job interviews. Frontiers in Psychology, 8, $1-13$.

Ruch, F. L., \& Ruch, W. W. (1967). The K Factor as a suppressor variable in predicting success in selling. Journal of Applied Psychology, 51, 201-204.

Ryan, A. M., Inceoglu, I., Bartram, D., Golubovich, J., Grand, J., Reeder, M., Derous, E., Nikolaou, I., \& Yao, X. (2015). Trends in testing: Highlights of a global survey. In I. Nikolaou \& J. K. Oostrom (Eds.), Employee recruitment, selection, and assessment: Contemporary issues for theory and practice (pp. 136-153). Psychology Press.

Salgado, J. F. (2016). A theoretical model of psychometric effects of faking on assessment procedures: Empirical findings and implications for personality at work. International Journal of 
Selection and Assessment, 24(3), 209-228.

Schermer, J. A., Krammer, G., \& Goffin, R. D. (2019). The General Factor of Personality and faking: A cautionary note on the meaningfulness of the GFP under different response conditions. Personality and Individual Differences, 137, 110-114.

Schilling, M., Becker, N., Grabenhorst, M. M., \& König, C. J. (2021). The relationship between cognitive ability and personality scores in selection situations: A meta-analysis. International Journal of Selection and Assessment. Advanced online publication. https://onlinelibrary.wiley.com/doi/pdf/10.1111/ ijsa. 12314

Schmit, M. J., \& Ryan, A. M. (1993). The Big Five in personnel selection: Factor structure in applicant and nonapplicant populations. Journal of Applied Psychology, 78(6), 966-974.

Schmitt, N., \& Oswald, F. L. (2006). The impact of corrections for faking on the validity of noncognitive measures in selection settings. Journal of Applied Psychology, 91(3), 613-621.

Sireci, S. G. (2009). Packing and unpacking sources of validity evidence: History repeats itself again. In R. W. Lissitz (Ed.), The concept of validity: Revisions, new directions, and applications (pp. 19 -37). Information Age.

Society for Industrial and Organizational Psychology, Inc. (2018). Principles for the validation and use of personnel selection procedures (5th Ed.). Author.

Speer, A. B., Christiansen, N. D., Melchers, K. G., König, C. J., \& Kleinmann, M. (2014). Establishing the cross-situational convergence of the ability to identify criteria: Consistency and prediction across similar and dissimilar assessment center exercises. Human Performance, 27(1), 44-60.

Spiro, R. L., \& Weitz, B. A. (1990). Adaptive selling: Conceptualization, measurement, and nomological validity. Journal of Marketing Research, 27, 61-69.

Tett, R. P., Anderson, M. G., Ho, C. L, Yang, T. S., Huang, L., \& Hanvongse, A. (2006). Seven nested questions about faking on personality tests: An overview and interactionist model of item-level response distortion. In R. L. Griffith \& M. H. Peterson (Eds.), A closer examination of applicant faking behavior (pp.43-83). Information Age Publishing.

Tett, R. P., \& Burnett, D. D. (2003). A personality trait-based interactionist model of job performance. Journal of Applied Psychology, 88(3), 500-517.

Tett, R. P., \& Christiansen, N. D. (2007). Personality tests at the crossroads: A response to Morgeson, Campion, Dipboye, Hollenbeck, Murphy, and Schmitt (2007). Personnel Psychology, 60(4), 967-993.

Tett, R. P., Freund, K. A., Christiansen, N. D., Fox, K. E., \& Coaster, J. (2012). Faking on self-report emotional intelligence and personality tests: Effects of faking opportunity, cognitive ability, and job type. Personality and Individual Differences, 52(2), 195-201.

Tett, R. P., Jackson, D. N., Rothstein, M., \& Reddon, J. R. (1999). Meta-analysis of bidirectional relations in personality-job performance research. Human Performance, 12(1), 1-29.

Tett, R. P., \& Simonet, D. V. (2011). Faking in personality assessment: A "multisaturation" perspective on faking as performance. Human Performance, 24(4), 302-321.

Tett, R. P., Simonet, D. V., Walser, B., \& Brown, C. (2013). Trait activation theory: Applications, developments, and implications for person-workplace fit. In N. D. Christiansen \& R. P.
Tett (Eds.), Handbook of personality at work (pp. 71-100). Routledge.

Tull, K. T. (1998). The effects of faking behavior on the prediction of sales performance using the Guilford Zimmerman Temperament Survey and the NEO Five Factor Inventory [ProQuest Information \& Learning]. Dissertation Abstracts International: Section B: The Sciences and Engineering, 58(10-B), 5688.

van Blijswijk, J. A., Van Breukelen, R. C., Franklin, A. L., Raadschelders, J. C., \& Slump, P. (2004). Beyond ethical codes: The management of integrity in the Netherlands tax and customs administration. Public Administration Review, 64(6), 718-727.

Vasilopoulos, N. L., \& Cucina, J. M. (2006). Faking on noncognitive measures: The interaction of cognitive ability and test characteristics. In R. L. Griffith \& M. H. Peterson (Eds.), A closer examination of applicant faking behavior (pp. 305-332). Information Age Publishing.

Walmsley, P. T., \& Sackett, P. R. (2013). Factors affecting potential personality retest improvement after initial failure. Human Performance, 26(5), 390-408.

Watts, L. L., Kuzmich, I., Leung, D. W., Gibson, C., \& Barsa, A. (2020). Impression management and overclaiming on job applications: Related to future sales performance? International Journal of Selection and Assessment, 29(1), 134-138.

Zickar, M. J., Gibby, R. E., \& Robie, C. (2004). Uncovering faking samples in applicant, incumbent, and experimental data sets: An application of mixed-model item response theory. Organizational Research Methods, 7, 168-190.

RECEIVED 01/18/21 ACCEPTED 03/22/21 